\title{
Experimental and Numerical-Driven Prediction of Automotive Shredder Residue Pyrolysis Pathways toward Gaseous Products
}

\author{
Rafał Ślefarski ${ }^{1, *}$, Joanna Jójka ${ }^{1}{ }^{1}$, Paweł Czyżewski ${ }^{1}$, Michał Gołębiewski ${ }^{1}$, Radosław Jankowski ${ }^{1}$, \\ Jarosław Markowski ${ }^{2}$ and Aneta Magdziarz ${ }^{3}$ (D) \\ 1 Institute of Thermal Engineering, Poznan University of Technology, 60-965 Poznan, Poland; \\ joanna.jojka@put.poznan.pl (J.J.); pawel.czyzewski@put.poznan.pl (P.C.); \\ michal.golebiewski@put.poznan.pl (M.G.); radoslaw.jankowski@put.poznan.pl (R.J.) \\ 2 Machine Design Institute, Poznan University of Technology, 60-965 Poznan, Poland; \\ jaroslaw.markowski@put.poznan.pl \\ 3 Faculty of Metals Engineering and Industrial Computer Science, AGH University of Science and Technology, \\ 30-059 Kraków, Poland; amagdzia@agh.edu.pl \\ * Correspondence: rafal.slefarski@put.poznan.pl; Tel.: +48-61-6652218
}

check for updates

Citation: Ślefarski, R.; Jójka, J.; Czyżewski, P.; Gołębiewski, M.; Jankowski, R.; Markowski, J.; Magdziarz, A. Experimental and Numerical-Driven Prediction of Automotive Shredder Residue Pyrolysis Pathways toward Gaseous Products. Energies 2021, 14, 1779. https://doi.org/10.3390/en14061779

Academic Editor: Paweł Ocłoń

Received: 1 February 2021

Accepted: 18 March 2021

Published: 23 March 2021

Publisher's Note: MDPI stays neutral with regard to jurisdictional claims in published maps and institutional affiliations.

Copyright: (c) 2021 by the authors. Licensee MDPI, Basel, Switzerland. This article is an open access article distributed under the terms and conditions of the Creative Commons Attribution (CC BY) license (https:// creativecommons.org/licenses/by/ $4.0 /)$.

\begin{abstract}
There has been a gradual increase in the field of parts recovery from cars that are withdrawn from use. However, the disposal of automotive shredder residue (ASR) still remains a significant problem. ASR is refuse derived fuel (RDF), which contains mainly plastics, fiber sponges, and rubbers in different proportions, and therefore a thermal treatment of selected waste samples is applied. The presented research includes thermogravimetry (TG) analysis and differential thermogravimetric (DTG) analysis, as well as a proximate and an ultimate analysis of the ASR samples. The obtained results were processed and used as an input for modelling. The numerical calculations focused on the identification of the ASR's average composition, the raw pyrolysis process product, its dry pyrolytic gas composition, and the combustible properties of the pyrolytic gases. The TGA analysis with three heating rate levels covered the temperature range from ambient to $800{ }^{\circ} \mathrm{C}$. The thermal decomposition of the studied samples was in three stages confirmed with three peaks observed at the temperatures 280,470 , and $670{ }^{\circ} \mathrm{C}$. The amount of solid residue grew with the heating rates and was in the range of $27-32 \mathrm{wt} \%$. The numerical calculation of the pyrolysis process showed that only $0.46 \mathrm{~kg}$ of dry gas were formed from $1 \mathrm{~kg}$ of ASR. The gas yield increased with the rising temperature, and, at the same time, its calorific value decreased from 19.22 down to $14.16 \mathrm{MJ} / \mathrm{m}^{3}$. This is due to the decomposition of $\mathrm{C}_{6+}$ hydrocarbons and the promotion of $\mathrm{CO}$ formation. The thermodynamic parameters of the combustion process for a pyrolytic gas air mixture, such as the adiabatic flame temperature and laminar flame speed, were higher than for methane and were, respectively, $2073{ }^{\circ} \mathrm{C}$ and $1.02 \mathrm{~m} / \mathrm{s}$.
\end{abstract}

Keywords: pyrolysis of RDF; thermal pyrolysis of plastics; ASR recycling; numerical modelling of pyrolysis process; thermogravimetric analysis

\section{Introduction}

Year by year, the global production of cars is growing (about 50 million/year), with a third of the cars being produced in Europe. Thus far, the most frequently raised issue in the context of the industry, has been the emission of carbon dioxide, blamed for causing climate change and releasing toxic substances, in particular, carbon monoxide, nitrogen oxides, and particulate matter. At present, the issue of recycling end-of-life vehicles is an increasingly popular topic. In recent decades, there has been a clear tendency to increase the use of plastics in place of formerly metal components.

The automotive industry is the third highest polymer-consuming sector, after the packaging and building industries. Unfortunately, many of these elements are mixtures of many different types of polymers [1]. The regulations currently being introduced counteract 
this tendency. According to the current European Directive 2000/53/EC on end-of-life vehicles, the recycling rate of materials from scrapped cars should be at least $95 \%$ (up to $10 \%$ energy recovery) [2].

However, there are millions of cars in use that are of a mixed polymer profile and will soon need to be disposed of. Due to the use of polymer mixtures, the problem of their recovery with the use of the currently available methods of plastic recycling is considerably difficult or even impossible to carry out [3]. In the first part of the demolition process of scrapped vehicles, useful parts can be recovered. Unrecovered residues are then compressed and directed to extract valuable ferrous and nonferrous metals. The leftovers from such a process are called automobile shredder residue (ASR). This consists of plastic, fiber and sponge, rubber, glass and wood, metal, and other materials [4,5]. ASR is a typical refuse derived fuel (RDF) fuel from the automotive sector.

More than $70 \%$ of the plastic used in automobiles comes from four polymers: polypropylene (PP), polyurethane (PUR), polyamides (PA), and polyvinyl chloride (PVC). The physical and chemical properties of selected ASR polymers are presented in the Table 1. Blends of two or even more types of polymers are commonly applied in vehicle elements [6]. The most common-mechanical-methods of recycling them are difficult to apply due to the heterogeneity of their composition. Many methods have been proposed for solving this problem; however, they have not yet found wide industrial application [7].

Non-recyclable fractions with a relatively high calorific value can be converted in special plants to the form of RDF. RDF is utilized in incineration plants or added for energetic processes in cement plants. However, this approach creates a negative environmental impact through carbon dioxide and toxic compound emissions. Regarding this issue, studies of RDF thermochemical conversion may become a reference for combustible waste recycling, like ASR. Plants powered by RDF can replace landfills or incineration plants in the future.

Much research has been done, and many solutions regarding the use of RDF fuel have been proposed in the literature. One of the considered methods is the thermochemical conversion of said plastic waste using pyrolysis and gasification technology [8,9]. Depending on the applied conditions, these technologies allow for the transformation of the feed supplied to the reactor into a flammable gas, liquid, or solid and, to a limited extent, control the flow of their fractions. The gaseous form of the product of plastic pyrolysis or gasification enables easier separation of the stream of generated gases [10]. Pyrolysis is a process of thermochemical decomposition of organic matter in the absence of oxygen with or without the use of catalysts [11].

Table 1. The physical and chemical properties of selected polymers [12-16].

\begin{tabular}{|c|c|c|c|c|c|c|c|}
\hline \multirow{2}{*}{ Physical Properties } & \multicolumn{7}{|c|}{ Type of Polymer } \\
\hline & PVC & PA6 & PA 6.6 & PP & PBT & PUR & PS \\
\hline High Heating Value [MJ/kg] & 23.9 & 26.5 & $\mathrm{n} / \mathrm{a}$ & 44.1 & 15.7 & 31.6 & 40.4 \\
\hline Density $\left[\mathrm{g} / \mathrm{cm}^{3}\right]$ & 1.5 & 1.13 & 1.14 & 0.91 & 1.35 & 1.51 & 1.04 \\
\hline Degradation temperature @1atm $\left[{ }^{\circ} \mathrm{C}\right]$ & 260 & 200 & 200 & 445 & 420 & 592 & 300 \\
\hline Melting point $\left[{ }^{\circ} \mathrm{C}\right]$ & 302 & 220 & 269 & 163 & 323 & $\mathrm{n} / \mathrm{a}$ & 340 \\
\hline
\end{tabular}

$\mathrm{n} / \mathrm{a}$ : not available in the literature, polybutylene terephthalate (PBT), polystyrene (PS).

Unfortunately, the nature of the pyrolysis process results in generating a greater amount of liquid and solid product, which is characterized by a diverse composition. In addition to chain hydrocarbons, it also contains nitrogen and sulphur compounds as well as polycyclic aromatic hydrocarbons (which vary, depending on the original composition of the fuel). The liquefaction process can be prevented by the use of a variety of catalysts [17]. However, this solution is characterized by high cost and a greater complexity than the thermal pyrolysis method. Therefore, the further development of pyrolysis technology in the context of plastics processing is both important and prospective. 
In thermal pyrolysis, high temperatures are required. This often results in low quality products. Thermal degradation without a catalyst introduces a wide range of products with a low molecular mass [18]. Therefore, most of the studies conducted have shown that catalytic pyrolysis is the best method to avoid the melting of ash in plastics, which occurs at low temperatures $[3,16,17]$. However, due to the additional difficulties in the form of a need to supply a catalyst, their consumption and the additional complication of the reactors, thermal, not catalytic, pyrolysis is preferred.

In thermal pyrolysis, nonorganic parts of the fuel can remain practically unchanged in the solid fraction of products. This enables the separation and recovery of this substance. Depending on the operating temperature of the reactor, the rate of heating, and the residence time in the reactor, it is possible to direct the process to obtain one of the three products: char, liquid oil, or gas. Gas production is dominant at high temperatures, those exceeding $500{ }^{\circ} \mathrm{C}$, and oil production is dominant at the lower temperatures, between 300 and $500{ }^{\circ} \mathrm{C}$. The high heating value $(\mathrm{HHV})$ of gas delivered from the pyrolysis process of $\mathrm{RDF}$ is typically in the range from 15 to $30 \mathrm{MJ} / \mathrm{m}^{3}$ [19], while oil products have their HHV around $40 \mathrm{MJ} / \mathrm{kg}$ [15].

The typical physico-chemical properties of different types of RDF fuel, next to plastics, have been previously investigated experimentally in many works. In [20], the authors investigated the pyrolysis behavior of three different municipal solid waste RDF samples in the temperature range from 500 to $900{ }^{\circ} \mathrm{C}$. They noticed that the ratio of released gas weight to volatile matter could be expressed by only temperature function for any tested conditions. Efika et al. focused on the influence of the process conditions on gas yields in municipal solid waste pyrolysis [21]. They observed the highest heating value of resulting gas $\left(24.8 \mathrm{MJ} / \mathrm{m}^{3}\right)$ at $800^{\circ} \mathrm{C}$ and a rapid heating rate $\left(350{ }^{\circ} \mathrm{C} / \mathrm{min}\right)$.

Porshnov et al. [22] studied the decomposition of typical RDF fuel (mixed municipal waste). They concluded that the thermal decomposition of RDF could be classified into four distinct phases. Within the first interval, from 0 to $200{ }^{\circ} \mathrm{C}$, mostly physical processes are taking place, like the evaporation of water or melting of plastic components. The second stage concerns the biomass decomposition, if any biomass is present. In the third phase, the pyrolytic decomposition of plastics is dominantly taking place, while charring of any leftovers is happening over $550{ }^{\circ} \mathrm{C}$.

Buah et al. [23] studied the influence of the temperature of municipal solid waste RDF pyrolysis on the gaseous product amount and calorific value. The calorific value of the resulting gas rose with the temperature, and the maximum value was equal to $16.7 \mathrm{MJ} / \mathrm{m}^{3}$ at $700{ }^{\circ} \mathrm{C}$. Cozzani et al. [24] investigated the conventional pyrolysis of municipal solid waste with $17 \mathrm{wt} \%$ of plastic. They observed an evident increase of the gas fraction at furnace temperatures over $600{ }^{\circ} \mathrm{C}$. They related this to the occurrence of tar-cracking reactions in the homogeneous phase. The composition of the resulting gas was strongly dependent on the reactor temperature.

When the hydrogen and carbon dioxide share increased with the rising reactor temperature, the carbon monoxide levels decreased. Rajca et al. [25] studied, both experimentally and numerically, the pyrolysis process of refuse-derived fuels consisting of a minimum of two types of materials: biomass and thermoplastic polymers. They found that the vast majority of the RDF (75 wt \%) was degraded before reaching $680{ }^{\circ} \mathrm{C}$, where the gas fraction was $42.9 \mathrm{wt} \%$. A further increase in temperature to $900{ }^{\circ} \mathrm{C}$ caused only a slight increase in the thermal degradation; however, the increased share of the gas went up to $49 \mathrm{wt} \%$.

The presented comparison between computer simulations and experimental studies demonstrated a good convergence of gas phase prediction, especially for carbon monoxide and hydrogen. The largest differences were found for methane, where the concentration of methane $\left(\mathrm{CH}_{4}\right)$ was twice as high as the concentration for a numerical prediction. This resulted in a change of the low heating value (LHV) value from 8.3 to $11.8 \mathrm{MJ} / \mathrm{m}^{3}$, respectively, for the experiment and the numerical calculation.

As ASR is a multi-component material, it is important to investigate the influence of its composition on the pyrolysis process. Yun et al. [26] investigated the pyrolysis 
characteristics of glass fiber reinforced plastic (GFPR), which is one of the components of ASF. They created isothermal conditions in a thermo-balance reactor (TBR) and a wire mesh reactor (WMR) to determine the mass loss curve, product yield, and kinetic parameters.

This research demonstrated that the amount of generated gas was low in the temperature range between 600 and $700{ }^{\circ} \mathrm{C}$ and started to increase significantly from 700 to $1000{ }^{\circ} \mathrm{C}$. In the case of the reaction time, the gas yield was low for $2 \mathrm{~s}$, but increased significantly from $4 \mathrm{~s}$ and remained at a similar level up to $10 \mathrm{~s}$. They observed that the temperature and reaction time increased resulting in promoted polymer scission and repolymerization in the WMR according to Diels-Alder reactions, intermolecular radical transfer, and random chain scissions. Haydary et al. [27] studied ASR pyrolysis in a laboratory scale screw type reactor. They observed high $\mathrm{H}_{2}$ and $\mathrm{CO}$ increase with a temperature rise associated with light hydrocarbons and a methane content decrease.

Zolezzi et al. [28] compared fast and conventional pyrolysis of ASR composed dominantly of rubber and plastics characterized by a high ash content $(27.3 \%)$. They observed maximal gas production ( $35 \%$ by weight of the initial ASR) for the conventional mode. Another composition ASR type fuel pyrolysis also characterized by a high ash content was investigated by Roh et al. [29]. In thermogravimetry (TG) and differential thermogravimetric (DTG) analysis, they observed three stages corresponding to individual components of the fuel samples. The amounts of $\mathrm{H}_{2}$ and $\mathrm{CO}$ as well as the general gas yield increased with rising temperature.

Singh et al. [30] investigated the pyrolysis of municipal plastic waste (MSW) from different countries using a lab scale pyrolysis reactor, as well as a TG/DTG apparatus. The fuel comprised PE, PP, PS, polyethylene terephthalate (PET), PVC, and others, studied separately and cumulatively. They observed that the early start reduction temperature of mixed samples was lower than for individual samples, equal to 310 and $350{ }^{\circ} \mathrm{C}$, respectively. They suggested a synergistic effect of sample mixing. This observation is consistent with the results presented in Han et al.'s study [31] on typical ASR pyrolysis.

In our study, we performed experimental and numerical analysis to understand the pyrolysis process of ASR samples. The proximate and ultimate analyses, as well as the TGA and DTG analyses of mixed and not-recycled parts of automotive plastics, were prepared as input parameters for numerical modelling. The TGA experiments were performed in non-isothermal conditions to measure the mass loss of the ASR sample with a constant heating rate. Numerical calculations were focused on the pyrolysis product characteristics, with the combustible properties of the pyrolytic gas as the most important parameter.

Calculations of the pyrolysis product composition were carried out with a perfectly stirred reactor (PSR), ensuring constant pressure, temperature, and a selected residence time. Cantera [32] models and the CRECK [33] mechanism were also applied. The gas composition, as well as its calorific value, adiabatic flame temperature, and speed were analyzed for each set of pyrolysis process parameters. The laminar flame speed of the dry gas was obtained with a freely propagating flame model using GRI-Mech 3.0 [34].

\section{Methods}

The flow chart of the study and methodology is presented in Figure 1. The results from the proximate and ultimate analyses of refuse derived fuels were used as input data for the numerical calculation of the pyrolysis gas composition. Thermogravimetric analysis was selected as the representative method for a set of pyrolysis process parameters. 


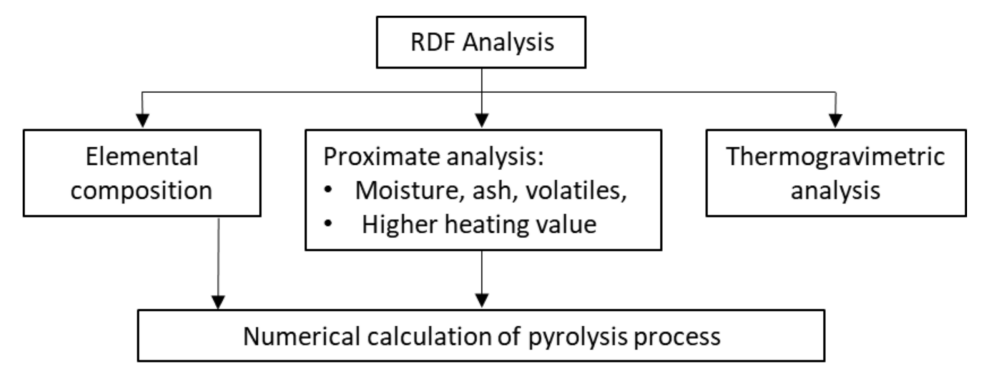

Figure 1. Flow chart of the study. Refuse derived fuel (RDF).

\subsection{The Elemental Analysis}

The automotive refuse derived fuel, after homogenization and the grinding process, was investigated using the Truspec CHN628 Leco analyzer, equipped with infrared (IR) and thermo-conductive detectors. The simultaneous determination of the carbon, hydrogen, and nitrogen content was based on the Dumas method. The sample was burned in a hightemperature furnace $\left(950{ }^{\circ} \mathrm{C}\right)$ in an oxygen atmosphere, to carbon dioxide $\left(\mathrm{CO}_{2}\right)$, water vapor $\left(\mathrm{H}_{2} \mathrm{O}\right)$, and nitrogen $\left(\mathrm{N}_{2}\right)$. Independent IR detectors were used for the simultaneous detection of carbon $(\mathrm{C})$ and hydrogen $(\mathrm{H})$, while the nitrogen $(\mathrm{N})$ content was measured using a thermal conductivity detection system. Figure 2 presents an ASR plastic sample before and after the grinding process.
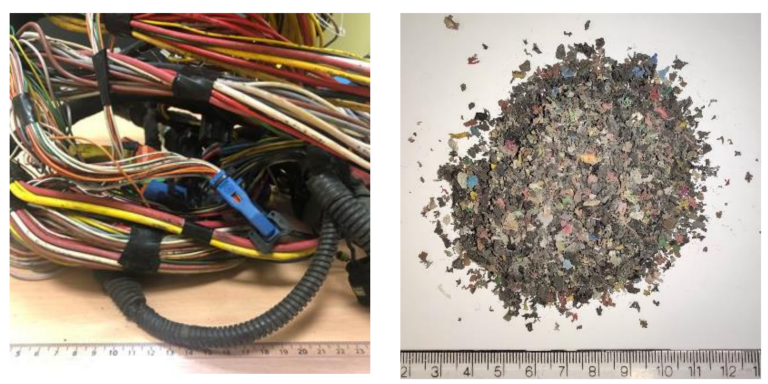

Figure 2. Automotive shredder residue (ASR) plastic sample before and after the grinding process.

\subsection{The Proximate Analysis}

During the proximate analysis, the moisture, volatiles, and ash content of the ASR fuel were determined. The moisture content was determined with the use of a drying oven method. An electric dryer (Binder E28) with thermostatic temperature control was used. The sample of the ASR before the drying process was ground to particles, with the diameter no larger than $0.2 \mathrm{~mm}$. The fuel drying process was carried out in an air atmosphere for $90 \mathrm{~min}$, in a temperature range of about $105-110{ }^{\circ} \mathrm{C}$. The weight loss of the sample was measured with an accuracy of $0.001 \mathrm{~g}$.

To determine the ash content, an incineration method was used, according to the EN 14775:(2010) [35] standard. The ASR sample, with its weight at approximately $10 \mathrm{~g}$, was introduced into a muffle furnace (Nabertherm LVT3) and heated to a temperature of $250{ }^{\circ} \mathrm{C}$ (annealed over $60 \mathrm{~min}$ ) and later up to $815^{\circ} \mathrm{C}$, with the sample annealing over $360 \mathrm{~min}$. After cooling the sample to the ambient temperature of the ash, the dish was weighed with the accuracy of $0.1 \mathrm{mg}$.

The determination of volatiles was performed according to the European Standard EN 15148-2009 [36]. The sample, with its weight around $1 \mathrm{~g}$, was placed in a Rademacher vessel with a cover, and heated to $900{ }^{\circ} \mathrm{C}$ for a period of $7 \mathrm{~min}$ in a muffle furnace. After the vessels cooled down, the sample was weighed with an accuracy of $0.0002 \mathrm{~g}$.

In addition, the gross calorific value of the automotive ASR of the fuel was established using a calorimetric bomb method, according to the ISO 1928:2009 standard [37]. The gross calorific value was determined at a constant volume with the reference temperature of $25^{\circ} \mathrm{C}$ in a bomb calorimeter. The bomb calorimeter was calibrated by benzoic acid 
incineration. The ASR was burned at a constant pressure. The resulting water was not condensed but was removed with flue gases. During the measurements, five samples of fuel were investigated, where the maximum gross calorific value difference was at the level of $0.6 \mathrm{MJ} / \mathrm{kg}$.

\subsection{The Thermogravimetric Analysis (TGA)}

The thermogravimetric analyses were performed using a Mettler Toledo TGA/SDTA 851 analyzer. For the thermal analyses (TG - thermogravimetric analysis and DTG-differential thermogravimetric analysis), the samples were placed in corundum $\left(\mathrm{Al}_{2} \mathrm{O}_{3}\right)$ crucibles. Approximately $5.3 \mathrm{mg}$ of ASR was heated from ambient temperature to the maximum temperature of the pyrolysis process, which was equal to $800{ }^{\circ} \mathrm{C}$, with three heating rate levels of 10,20 , and $30^{\circ} \mathrm{C} / \mathrm{min}$. The tests were carried out in a nitrogen atmosphere with a flow of $40 \mathrm{~mL} / \mathrm{min}$. The two samples were measured under exactly the same conditions, including the temperature range, atmosphere, and heating rate. The TG and DTA curves for each of the samples were obtained as the outputs for the pyrolysis process.

\subsection{The Modelling Procedure}

The main purpose of the numerical analysis was a determination of the pyrolytic gas composition and its combustible properties. The investigation was divided into the following four steps:

1. Identification of the automotive waste average composition,

2. Calculation of the raw pyrolysis process products,

3. Determination of the dry pyrolytic gas composition, and

4. Evaluation of the pyrolytic gases combustible properties.

The calculations were carried out with the Cantera software, which comes with a number of zero- and one-dimensional models. Reactor and flame models are available for a number of well-defined and commonly encountered phenomena [32].

An IdealGasReactor was chosen, which represents the perfectly stirred reactor class (PSR) of the zero-dimensional models, with a constant pressure and temperature, and a conservation of the selected residence times. The possibility to mark the percentage share of the exact species present in the sample was limited; therefore, the ultimate and proximate analysis results were taken as an initial composition of the sample (ASR 1). The influence of the residence time, the process temperature, and the pressure on the product composition was investigated. The modelling procedure performance was confronted with an experimental outcome of a corresponding automotive waste sample (ASR 2) as analyzed by Yun et al. [26].

The pyrolysis process products were cooled in a second PSR reactor to obtain the raw off-gas composition $(\mathrm{P})$ for the standard state conditions $\left(25^{\circ} \mathrm{C}\right.$ and $\left.101,325 \mathrm{~Pa}\right)$. The composition of the pyrolytic gas in the PSRs was determined with a CRECK [33] mechanism. A significant amount of long chain and aromatic hydrocarbons was expected, and therefore, datasets for $C_{1}-C_{16}$, soot, and nitrogen chemistry were chosen (621 species).

The composition of the overall pyrolysis process products was divided into five groups: $\mathrm{H}_{2} \mathrm{O}, \mathrm{H}_{2}, \mathrm{CO}-\mathrm{CO}_{2}, \mathrm{C}_{1}-\mathrm{C}_{4}$, and $\mathrm{C}_{6+}$ and others. We assumed that the dry pyrolytic gas (DG) consisted of elements characterized by a condensation temperature below $25^{\circ} \mathrm{C}$. Therefore, the highest density yield $\mathrm{C}_{6}+$ was rejected from the resulting product gas, as well as the remaining $\mathrm{H}_{2} \mathrm{O}$ water vapor, in order to obtain the proper dry gas composition.

The lower heating value of the dry gas $\left(\mathrm{LHV}_{\mathrm{DG}}\right)$ and the raw pyrolysis products $\left(\mathrm{LHV}_{\mathrm{P}}\right)$ were calculated differing from the standard enthalpy of formation. The LHV value of the received gas was measured for the pyrolysis process temperature and pressure (up to $1000{ }^{\circ} \mathrm{C}$ and 5 bars).

The adiabatic flame temperature $\left(\mathrm{T}_{\mathrm{A} D G}\right)$ and the laminar flame speed $\left(\mathrm{S}_{\mathrm{L} D G}\right)$ were estimated with a 1D FreeFlame model (1D FF). The flame speed values were investigated for stoichiometric mixtures of air and dry pyrolysis gas. During the $\mathrm{T}_{\mathrm{A}} \mathrm{DG}$ and $\mathrm{S}_{\mathrm{L} \text { DG }}$ calculation, the fuel composition was limited to the samples with a mass fraction greater 
than $0.01\left(\mathrm{H}_{2}, \mathrm{CO}, \mathrm{CO}_{2}\right.$, and $\left.\mathrm{C}_{1}-\mathrm{C}_{3}\right)$; therefore, a GRI-Mech 3.0 mechanism was available for use in the flame speed calculations. A workflow summary is presented in Figure 3.

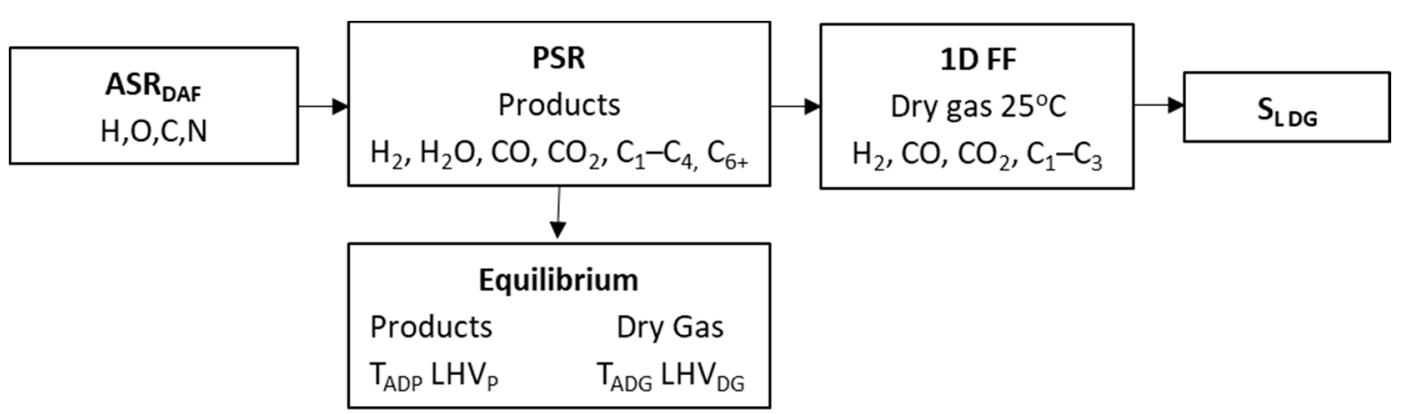

Figure 3. Numerical modelling workflow. Dry ash free (DAF), perfectly stirred reactor (PSR), 1D FreeFlame model (1D FF), laminar flame speed $\left(\mathrm{S}_{\mathrm{L}} \mathrm{DG}\right)$, lower heating value of the dry gas $\left(\mathrm{LHV}_{\mathrm{DG}}\right)$, and raw pyrolysis products $\left(\mathrm{LHV}_{\mathrm{P}}\right)$.

\section{Results and Discussion}

\subsection{Automotive Refuse Derived Fuel Characteristics}

The physical and chemical properties of the mixture of automotive plastics are presented in Table 2.

Table 2. Characterization of ASR from automotive plastics.

\begin{tabular}{cccccccc}
\hline \multirow{2}{*}{ ASR Fuel } & \multirow{2}{*}{$\begin{array}{c}\text { Gross Calorific Value } \\
{[\mathbf{M J} / \mathbf{k g}]}\end{array}$} & \multicolumn{3}{c}{ Ultimate Analysis [wt\%] } & \multicolumn{3}{c}{ Proximate Analysis [wt\%] } \\
\cline { 3 - 7 } & & $\mathbf{C}^{\mathbf{1}}$ & $\mathbf{H}^{\mathbf{1}}$ & $\mathbf{N}^{\mathbf{1}}$ & Moisture & Ash & Volatiles \\
\hline Sample 1 & \multirow{2}{*}{$23.5 \pm 0.6$} & 41.4 & 5.4 & 24.1 & & & \\
Sample 2 & & 43.1 & 5.7 & 37.8 & $0.84 \pm 0.06$ & $26.7 \pm 1.1$ \\
Sample 3 & & 41.6 & 5.5 & 28.2 & & & \\
\hline
\end{tabular}

${ }^{1}$ accuracy of ultimate analysis is: $\mathrm{C}=0.15 \mathrm{wt} \% ; \mathrm{H}=0.02 \mathrm{wt} \% ; \mathrm{N}=0.03 \mathrm{wt} \%$.

Different types of plastics have different compositions, including the moisture content $(\mathrm{W})$, volatile matter (VM), and ash (A) content. For the selected type of polymers, the VM content was in the range between 86 and $99.5 \mathrm{wt} \%$, respectively, for polyethylene terephthalate (PET) and polyamide (PA). The ash and moisture content was low, up to 2 and $1 \mathrm{wt} \%$, respectively [16]. The volatile matter and ash content are the major factors that influence the product composition in the pyrolysis process.

The high value of VM promotes liquid oil production, while a high ash content increased the gaseous yield and char formation. The data presented in Table 2 confirmed the multi-component nature of the tested material. The high content of ash that was measured could be the result of additives in the plastics to improve their properties, such as the optical properties, flexibility, tensile strength, and hardness.

The most commonly used additives in different types of plastics are plasticizers, flame retardants, antioxidants, light and heat stabilizers, lubricants, pigments, antistatic agents, slip compounds, and thermal stabilizers [38]. The second group of materials that increases the ash content is polymer matrix composites (PMC), which are used to produce lightweight vehicles. They are divided into two groups: fiber sheet molding compounds (SMC) and carbon or glass fiber reinforced polymer matrix composites [39].

The average higher heating value of the analyzed fuel was $23.5 \mathrm{MJ} / \mathrm{kg}$. This value is similar for typical energetic coal assortments, and higher than the most common types of biomass. In relation to an individual plastic, the measured HHV was close to polyvinyl chloride or polyamide. Based on the proximate analysis of mixed plastics (high A content and low VM content), the pyrolysis of such ASR will promote an increase in the gas yield in comparison to the pyrolysis of a single plastic. 


\subsection{TGA Analysis}

Figures 4 and 5 present the thermal behavior of the studied fuels under a nitrogen atmosphere, simulating the pyrolysis process. The TG analysis showed the weight loss of the investigated material during its thermal conversion process, while the DTG analysis allowed us to determine the temperature at which the rate of decomposition of the tested material reached the maximum values. To guarantee the validity of the results obtained during the analysis due to the possibility of heterogeneity of the sample, the TG analysis was repeated twice. The samples were analyzed in non-isothermal conditions at a constant heating rate of $10^{\circ} \mathrm{C} / \mathrm{min}$.

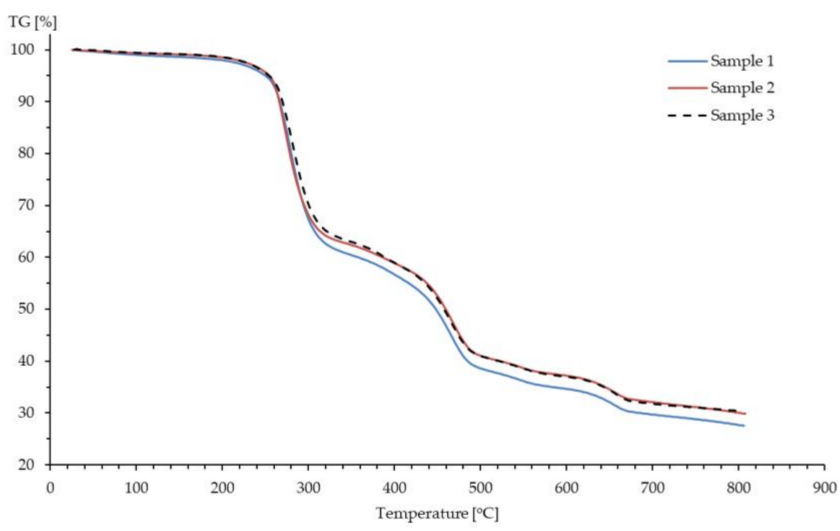

Figure 4. Thermogravimetry (TG) analysis for the ASR sample pyrolysis process.

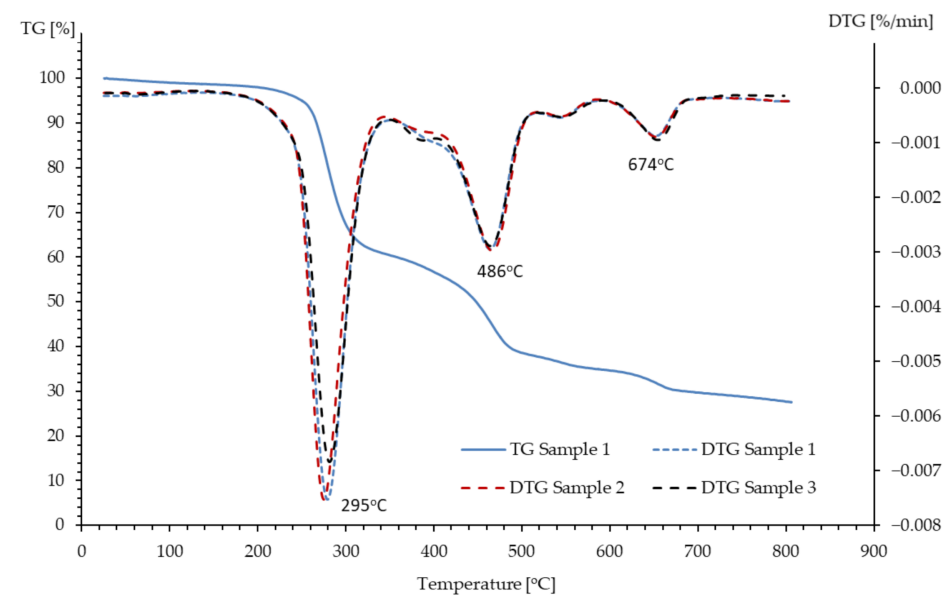

Figure 5. Differential thermogravimetric (DTG) curves for the ASR sample pyrolysis.

As can be seen in Figures 4 and 5, the results of the pyrolysis process for the repetitions are comparable. The results show that a significant part of the material underwent a thermal degradation in the temperature range of up to $480{ }^{\circ} \mathrm{C}$ (Sample $1-65 \mathrm{wt} \%$ and Samples 2 and 3-63 wt\%). The next important weight loss (about $11 \mathrm{wt} \%$ ) occurred in the temperature range of up to $670{ }^{\circ} \mathrm{C}$. After the end of the pyrolysis process, at the temperature of $800{ }^{\circ} \mathrm{C}$, the residues of the charge material were at levels of approximately $28 \mathrm{wt} \%$ (Sample 1) and $29 \mathrm{wt} \%$ (Sample 2 and 3).

The DTG analysis confirmed the multi-component structure of the tested fuel, with three peaks visible. The first peak shows a decomposition temperature of around $287^{\circ} \mathrm{C}$ and corresponds to the thermal decomposition profiles of such polymers as PA and PVC. The second decomposition temperature is about $470{ }^{\circ} \mathrm{C}$ and is related to the breakdown of polymers, such as PE, PP, and polybutylene terephthalate (PBT) [30]. The smallest but distinct peak was noted for about $670{ }^{\circ} \mathrm{C}$ and is connected with the pyrolysis of polyurethanes and materials used as additives in ASR materials. 
The obtained TG and DTG curves for the analyzed samples are almost identical, which proves the homogeneity of the investigated samples. Therefore, the influence of the heating rate on the pyrolysis process was studied only for sample 1 . The analysis was carried out for three heating rate levels $\left(10,20\right.$, and $\left.30^{\circ} \mathrm{C} / \mathrm{min}\right)$ and the results in the form of the TG and DTG curves are presented in Figure 6.

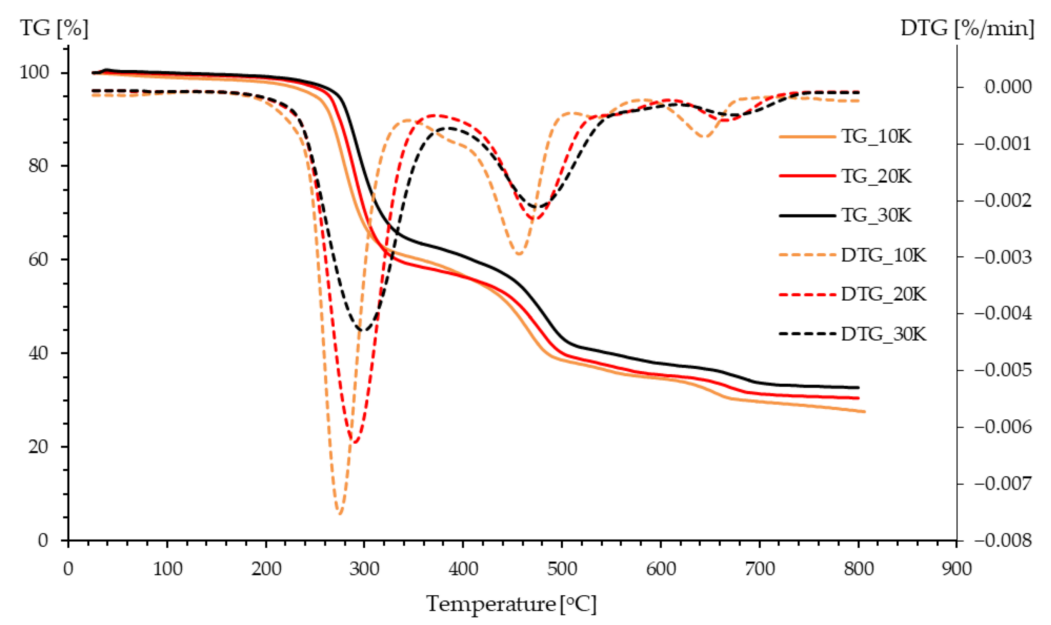

Figure 6. The heating rate effect on the TG and DTG curves for the Sample 1 pyrolysis.

Increasing the heating rate did not affect the course of the pyrolysis process, but the TG curves were shifted toward higher temperatures. An influence of the heating rate on the amount of products obtained was observed. The difference between the two extreme cases was over $5 \%$ ( $27 \%$ versus $32 \%$ of the original sample mass). This is also connected with the reduction of the gaseous fraction in the reaction products. In a situation where the aim is to obtain the largest possible volume of valuable gaseous products, increasing the sample heating speed had the opposite effect.

\subsection{Numerical Calculation of Pyrolysis Process}

The numerical calculation of the pyrolysis process of the ASR sample was carried out for a constant temperature, ranging from 600 to $1000{ }^{\circ} \mathrm{C}$. Different residence times were applied, starting from 2 up to $90 \mathrm{~s}$. The ultimate and proximate analysis results for Samples 1,2 , and 3 were averaged and introduced with the initial mixture of properties, referred to as ASR 1 fuel. Additionally, a sample containing a glass fiber reinforced plastic (ASR 2 [26]) was investigated and used to validate the modelling procedure.

The share of the nitrogen $\left(\mathrm{N}_{2}\right)$ as a possible inert or carrier gas for the pyrolysis process was neglected, and thus only elemental nitrogen was taken into consideration. The elemental oxygen content was calculated as a complementary value for the averaged initial mixture. The data sets were processed to achieve a dry ash-free $\left(\mathrm{ASR}_{\mathrm{DAF}}\right)$ initial composition and are presented in Table 3.

Table 3. Characterization of the sample compositions for the numerical calculations.

\begin{tabular}{cccccccc}
\hline \multirow{2}{*}{ ASR Fuel } & \multicolumn{3}{c}{ Ultimate Analysis [wt\%] } & \multicolumn{3}{c}{ Proximate Analysis [wt \%] } \\
\cline { 2 - 8 } & $\mathbf{C}$ & H & N & O & Moisture & Ash & Volatiles \\
\hline ASR 1 & 42.03 & 5.52 & 0.30 & 20.27 & 0.84 & 26.70 & 66.30 \\
ASR 2 [26] & 60.26 & 5.37 & 0.44 & 11.37 & 1.57 & 22.20 & 71.19 \\
\hline
\end{tabular}

A comparison of the numerical and experimental results for ASR 2 was prepared and is shown in Figure 7. A general underestimation of the $\mathrm{CO}_{2}$ production was recorded, while the $\mathrm{CO}$ shares were overestimated. A similar effect was observed for the pyrolysis of a biomass-based waste, with CRECK by Rajca et al. [25]; however, a significantly greater 
share of $\mathrm{CO}_{2}$ was formed, compared to the ASR 2 results. The overall $\mathrm{CO}-\mathrm{CO}_{2}$ mass yield corresponded with the analogous values for the experimental outcome, as well as the $C_{1}-C_{2}$ fraction contribution. The calculations indicated slightly higher rates for the hydrogen and ethylene formation compared with the test results. The total gaseous product shares for ASR 2 did not exceed $34.1 \mathrm{wt} \%$, while the experiment showed their maximum at $1000{ }^{\circ} \mathrm{C}-43.1 \%$.
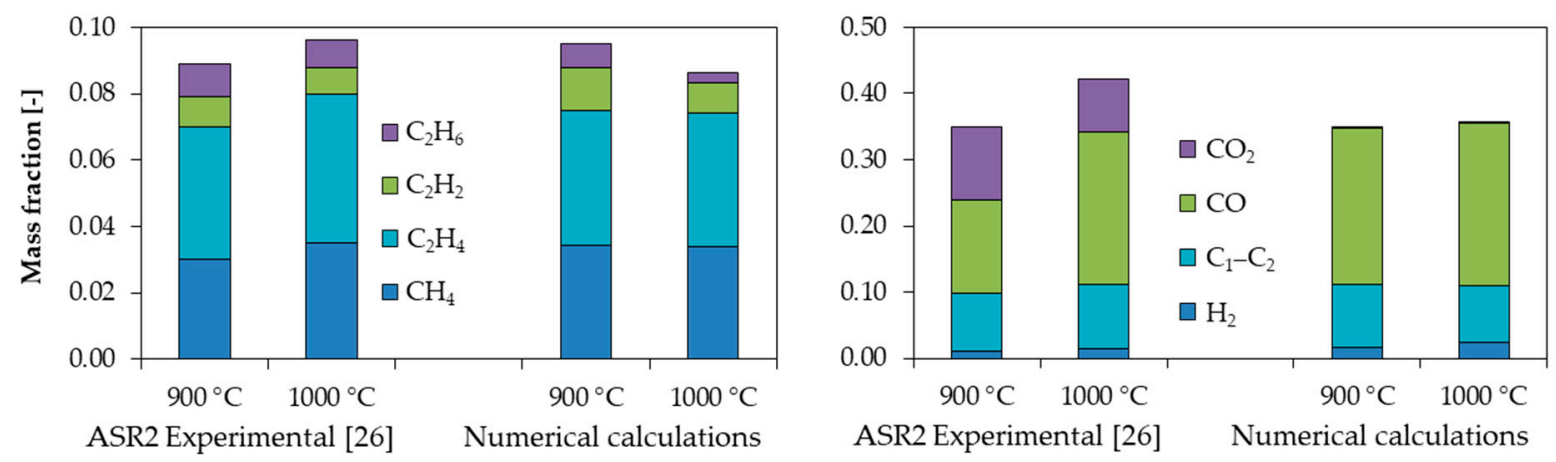

Figure 7. Comparison of the fraction distribution for the ASR 2 raw pyrolysis product-experimental [26] and numerical outcomes.

ASR 1 and ASR 2 were characterized by similar $\mathrm{H}, \mathrm{N}$, and ash shares, although the carbon fraction was significantly higher for the glass-fiber reinforced waste. Therefore, a great amount of high-density aromatic hydrocarbons were noted for the ASR 2 (62.8\% of the produced raw gas) as the oxygen availability was limited. The detailed composition of the pyrolysis process products for ASR 1 is shown in Table 4 . The data sets present selected values of the investigated pyrolysis temperature range (from 600 to $1000{ }^{\circ} \mathrm{C}$ ).

Table 4. Characterization of the product composition for numerical calculations—raw pyrolytic gas, residence time $2 \mathrm{~s}$, fuel ASR 1.

\begin{tabular}{|c|c|c|c|c|c|c|c|c|c|c|c|c|}
\hline \multirow{2}{*}{$\begin{array}{l}\text { Pyrolysis Temperature } \\
{\left[{ }^{\circ} \mathrm{C}\right]}\end{array}$} & \multicolumn{11}{|c|}{ Raw Product Gas Composition [wt $\%$ ] } & \multirow[b]{2}{*}{$\left(\mathrm{C}_{6} \mathrm{H}_{6}\right)$} \\
\hline & $\mathbf{H}_{2}$ & $\mathrm{H}_{2} \mathrm{O}$ & $\mathrm{CO}$ & $\mathrm{CO}_{2}$ & $\mathrm{CH}_{4}$ & $\mathrm{C}_{2} \mathrm{H}_{6}$ & $\mathrm{C}_{2} \mathrm{H}_{4}$ & $\mathrm{C}_{2} \mathrm{H}_{2}$ & $\mathrm{C}_{3} \mathrm{H}_{8}$ & $\mathrm{C}_{4} \mathrm{H}_{10}$ & $\mathrm{C}_{6+}$ & \\
\hline 600 & 2.1 & 8.3 & 35.3 & 2.5 & 2.7 & 1.5 & 1.6 & 2.5 & 1.9 & 2.4 & 31.9 & 15.4 \\
\hline 700 & 1.8 & 8.0 & 36.8 & 2.4 & 6.1 & 1.6 & 3.1 & 2.1 & 1.2 & 0.8 & 29.9 & 15.1 \\
\hline 800 & 2.0 & 7.2 & 38.9 & 2.3 & 7.1 & 1.1 & 5.0 & 1.3 & 0.5 & - & 30.6 & 14.4 \\
\hline 900 & 2.9 & 4.9 & 42.5 & 2.4 & 6.2 & 0.5 & 5.1 & 1.0 & - & - & 30.3 & 11.9 \\
\hline 1000 & 3.9 & 2.9 & 46.7 & 1.6 & 4.8 & 0.1 & 3.6 & 1.5 & - & - & 32.0 & 7.9 \\
\hline
\end{tabular}

The lowest pyrolysis temperatures were connected with a wider range of light hydrocarbons in the off-gas, in a summary given as $C_{1}-C_{4}$. The highest mass yield of products was held by $\mathrm{CO}$ and the dense fraction of aromatic hydrocarbons-mostly benzene and heavy polycyclic aromatic hydrocarbons (PAHs), which are the gas phase precursors of soot formation [40]. The soot formation process with PAH is governed by a well-known HACA mechanism (hydrogen abstraction acetylene addition) [41].

The consumption of benzene, and the subsequent PAH formation process, is intensified with the temperature rise and the availability of fuel, which was visible for ASR2-its PAH share increased from $42.3 \%$ to $55.2 \%$, while the benzene share decreased from $21.7 \%$ to $7.6 \%$. The toluene and phenol shares were also tracked and added to the overall $\mathrm{C}_{6}{ }^{+}$ fraction, which is expected to be extracted from the gas phase within the cooling of the process products. The overall distribution of the ASR 1 mass yield is shown in Figure 8. 


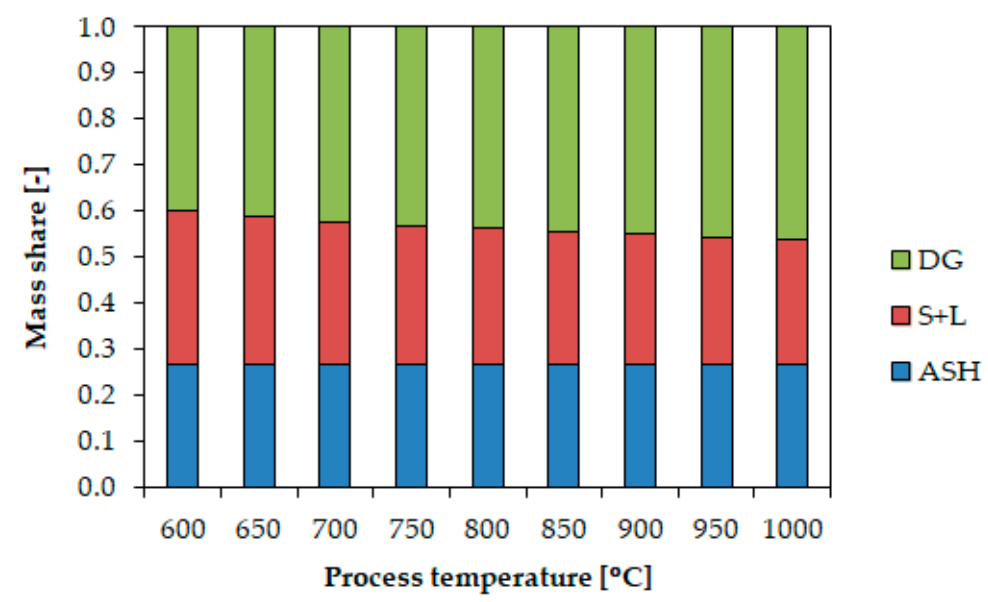

Figure 8. Distribution of the ASR 1 product fractions, $25^{\circ} \mathrm{C}$ and residence time $2 \mathrm{~s}$. Dry gas (DG), solid and liquid products $(\mathrm{S}+\mathrm{L})$, and ash (ASH).

The influence of the different residence times from 2 to $90 \mathrm{~s}$ was investigated for the pyrolysis process temperature of $800{ }^{\circ} \mathrm{C}$. There was a significant rise in the $\mathrm{CO}(38.9 \%$ to $42.9 \%)$ and $\mathrm{CO}_{2}(2.3 \%$ to $3.5 \%)$ shares for the longest time considered $(90 \mathrm{~s})$. The $\mathrm{C}_{6} \mathrm{H}_{6}$ contribution lowered with the extension of the reaction time-from $14.1 \%$ to $10.7 \%$, while the PAH share rose. A summary amount of light hydrocarbons was constant and at about $15.8 \%$, although distribution of the key $\mathrm{C}_{1}-\mathrm{C}_{4}$ types changed over the time. The methane formation was intensified-the share increased from $7.1 \%$ up to $10.8 \%$, while the ethylene fraction dropped from $5.1 \%$ to $3 \%$. Additionally, traces of acetylene and ethane were present, as well as ammonia and hydrogen cyanide (less than $1 \%$ ). The residence time impact on the gas composition was rearranged and is shown in Figure 9.

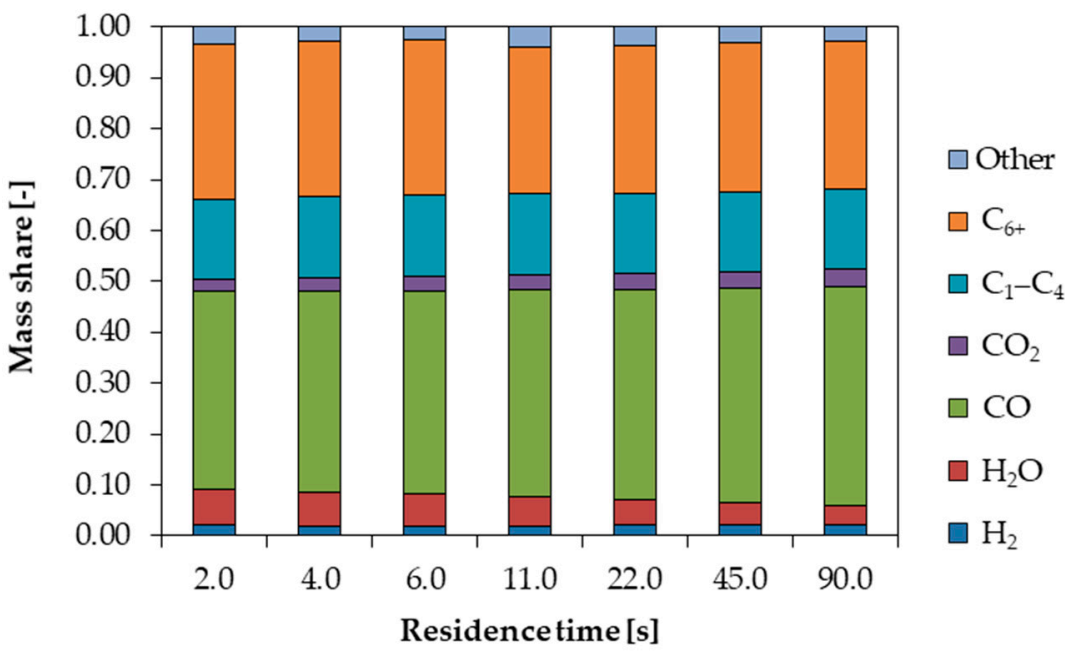

Figure 9. Distribution of the ASR 1 pyrolytic gas fractions as a function of the residence time; process temperature at $800{ }^{\circ} \mathrm{C}$.

The raw pyrolysis product was processed to determine the dry gas composition, which consisted of $\mathrm{H}_{2}, \mathrm{CO}, \mathrm{CO}_{2}$, and $\mathrm{C}_{1}-\mathrm{C}_{3}$. The evaluation of the pyrolytic gas combustible properties was carried out with $\mathrm{LHV}$ and $\mathrm{T}_{\mathrm{AD}}$ as the main indicators for both cases-the raw product $(\mathrm{P})$ and the resulting dry gas $(\mathrm{DG})$. The laminar flame speed $\left(\mathrm{S}_{\mathrm{L}}\right)$ characteristic of the dry gas was settled and is shown in Figure 10. 

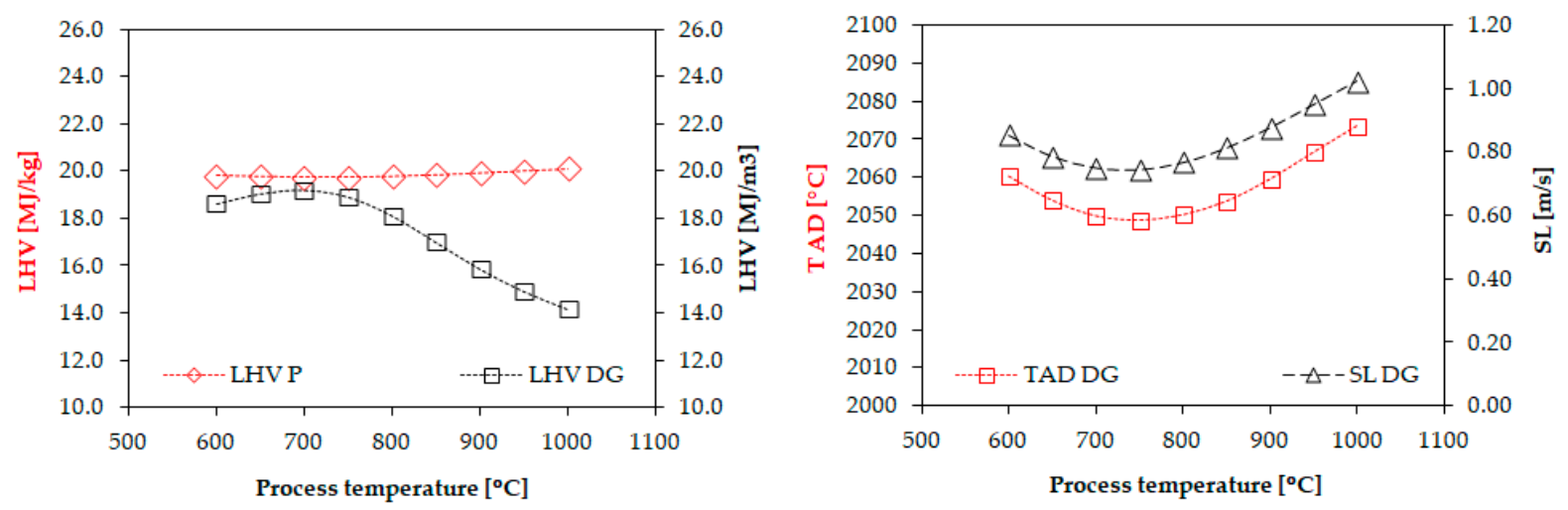

Figure 10. Thermodynamic properties of the raw and dry gas as a function of the pyrolysis processes temperature; residence time of $2 \mathrm{~s}$.

Calorific values of the raw process products were lower than the experimental results, with an average value of $19.87 \mathrm{MJ}$ per $\mathrm{kg}$ of ASR 1 . The dry gas combustible properties varied with the pyrolysis process operating conditions-from 14.16 up to $19.22 \mathrm{MJ}$ per 1 standard $\mathrm{m}^{3}$ of the dry gas. The highest $\mathrm{LHV}$ DG values were observed for the moderate pyrolysis process temperatures, ranging from 700 to $800^{\circ} \mathrm{C}$. The averaged mass share of the dry gas in the ASR 1 was estimated at $0.44 \mathrm{~kg}$ per $1 \mathrm{~kg}$ ASR 1 , which corresponds to the energy of $10.26 \mathrm{MJ}$ per $1 \mathrm{~kg}$ of ASR 1 . The dry gas mass yield rose with temperature, which balanced out the decreasing trend observed for the dry gas calorific value.

The lowest flame speeds $(0.75 \mathrm{~m} / \mathrm{s})$ were achieved subsequently for the considered moderate temperatures, which was a result of an increased share of the lightweight hydrocarbons $-15 \%$ of the raw product gas for $800{ }^{\circ} \mathrm{C}$. The real values for the modelled ASR 1 dry gas could be relatively lower, which is connected with the general CO over-prediction, which partially took place instead of $\mathrm{CO}_{2}$ formation.

The maximum value of the laminar flame speed was recorded for the process temperature of $1000{ }^{\circ} \mathrm{C}$ and amounted to $1.02 \mathrm{~m} / \mathrm{s}$-that is, 2.5-times higher than for a pure methane fuel. The discussed conditions were characterized by the highest achieved mass share of $\mathrm{H}_{2}$-around $3 \%$ of the raw product gas (35\% vol.), which amounts to $6.3 \%$ of the dry gas ( $47 \%$ vol.). The significant share of hydrogen also raised the adiabatic flame temperature to $2073{ }^{\circ} \mathrm{C}$, while the corresponding methane temperature was $1963^{\circ} \mathrm{C}$.

\section{Conclusions}

In this study, pyrolysis analysis, using the TGA-DTGA technique and numerical calculations, was carried out with ASR samples. The most important information includes the proximate and ultimate analyses, the thermal conversion process, the resulting gas composition, as well as the process parameters that influenced the pyrolysis products.

The conducted research led to the formulation of the following insights:

- the large amount of ash in the proximate analysis proves that there was a large share of fillers in the tested samples;

- $\quad$ around $70 \%$ of the mass of the tested samples underwent thermal decomposition mainly in three stages at temperatures ranges of about 280,470 , and $670{ }^{\circ} \mathrm{C}$;

- the mass of solid residue grew with increases in the heating rate levels;

- the highest calorific values of the dry pyrolytic gas corresponded to the moderate pyrolysis process temperatures $\left(700-800{ }^{\circ} \mathrm{C}\right)$, which is a result of the peak value of the hydrocarbon share $-15 \mathrm{wt} \%$ of $\mathrm{C}_{1}-\mathrm{C}_{3}$; and

- the averaged adiabatic flame temperature was $2057^{\circ} \mathrm{C}$, which is $94^{\circ} \mathrm{C}$ greater than in the case of methane combustion, while the mean value for the laminar flame speed was $0.84 \mathrm{~m} / \mathrm{s}$ due to the high volumetric share of hydrogen in the obtained dry gas fuel.

The conducted research shows that the gas received from the ASR pyrolysis process can be used as an energetic fuel. However, the thermodynamic parameters describing 
the combustion process differ from typical hydrocarbon fuels, which has to be considered when designing combustion systems by applying specialized solutions [42].

Author Contributions: Conceptualization: R.Ś. and J.M.; methodology: R.Ś. and P.C.; numerical methodology and calculation: J.J.; formal analysis: R.Ś.; resources: P.C., R.J., and M.G.; investigation: P.C., A.M., R.J., and M.G.; writing—original draft preparation: R.Ś., P.C., and J.J.; writing-review and editing: A.M. and R.Ś.; supervision: R.Ś.; project administration: J.M. All authors have read and agreed to the published version of the manuscript.

Funding: This research was funded by Rector of Poznan University of Technology, grant number 33/32/SIGR/0005, entitled "Development of a comprehensive technology for the utilization of polymer waste from the automotive industry in the Poznan area".

Institutional Review Board Statement: Not applicable.

Informed Consent Statement: Not applicable.

Data Availability Statement: Not applicable.

Conflicts of Interest: The authors declare no conflict of interest.

$\begin{array}{ll}\text { Abbreviations } \\ \text { A } & \text { ash } \\ \text { ASRDAF } & \text { automobile shredder residuedry ash free } \\ \text { DTGDG } & \begin{array}{l}\text { differential thermogravimetric analysisdry gas } \\ \text { high heating value }\end{array} \\ \text { HHV } & \begin{array}{l}\text { infrared detector } \\ \text { IR }\end{array} \\ \text { LHVP } & \text { low heating valueproduct (raw pyrolysis product) } \\ \text { PA } & \text { polyamide } \\ \text { PBT } & \text { polybutylene terephthalate } \\ \text { PE } & \text { polyethylene } \\ \text { PET } & \text { polyethylene terephthalate } \\ \text { PMC } & \text { polymer matrix composites } \\ \text { PP } & \text { polypropylene } \\ \text { PUR } & \text { polyurethane } \\ \text { PVC } & \text { polyvinyl } \\ \text { RDFSL } & \text { refuse delivered fuelslaminar flame speed } \\ \text { SMC } & \text { sheet moulding compound } \\ \text { TGTAD } & \text { thermogravimetric analysisadiabatic flame temperature } \\ \text { VM } & \text { volatile matter } \\ \text { W } & \text { moisture }\end{array}$

\section{References}

1. Czarnecka-Komorowska, D.; Wiszumirska, K. Sustainability design of plastic packaging for the Circular Economy. Polimery 2020, 65, 8-17. [CrossRef]

2. Orliński, S. Recykling materiałów polimerowych z samochodów wycofanych z eksploatacji. Logistyka 2014, 6, 8170-8177.

3. Al-Salem, S.M.; Antelava, A.; Constantinou, A.; Manos, G.; Dutta, A. A review on thermal and catalytic pyrolysis of plastic solid waste (PSW). J. Environ. Manag. 2017, 197, 177-198. [CrossRef]

4. Ho-suk, J. Development of Physical Separation System for Resource Recycling of ASR; Korea Ministry of Environment: Sejong City, Korea, 2016.

5. Inglezakis, V.J.; Zorpas, A.A. Automotive shredder residue (ASR): A rapidly increasing waste stream waiting for a sustainable response. WIT Trans. Ecol. Environ. 2009, 120, 835-843. [CrossRef]

6. Datta, J.; Błażek, K.; Włoch, M.; Bukowski, R. A New Approach to Chemical Recycling of Polyamide 6.6 and Synthesis of Polyurethanes with Recovered Intermediates. J. Polym. Environ. 2018, 26, 4415-4429. [CrossRef]

7. Rybarczyk, D.; Jędryczka, C.; Regulski, R.; Sędziak, D.; Netter, K.; Czarnecka-Komorowska, D.; Barczewski, M.; Barański, M. Assessment of the electrostatic separation effectiveness of plastic waste using a vision system. Sensors 2020, 20, 7201. [CrossRef]

8. $\mathrm{Wu}, \mathrm{C}$.; Williams, P.T. Pyrolysis-gasification of plastics, mixed plastics and real-world plastic waste with and without Ni-Mg-Al catalyst. Fuel 2010, 89, 3022-3032. [CrossRef]

9. Sieradzka, M.; Rajca, P.; Zajemska, M.; Mlonka-Mędrala, A.; Magdziarz, A. Prediction of gaseous products from refuse derived fuel pyrolysis using chemical modelling software-Ansys Chemkin-Pro. J. Clean. Prod. 2020, 248, 119277. [CrossRef] 
10. Prasad, R.; Shaner, R.L.; Doshi, K.J. Comparison of Membranes with Other Gas Separation Technologies. In Polymeric Gas Separation Membranes; CRC Press Taylor\&Francis Group: Boca Raton, FL, USA, 1994; pp. 531-614.

11. Basu, P. Chapter 3-Pyrolysis and Torrefaction. In Biomass Gasification and Pyrolysis; Elsevier Inc.; Academic Press: Boston, MA, USA, 2010; pp. 65-96, ISBN 978-0-12-374988-8.

12. Barikani, M.; Honarkar, H.; Barikani, M. Synthesis and characterization of chitosan-based polyurethane elastomer dispersions. Mon. Chem. 2010, 141, 653-659. [CrossRef]

13. Klapiszewski, Ł.; Bula, K.; Sobczak, M.; Jesionowski, T. Influence of Processing Conditions on the Thermal Stability and Mechanical Properties of PP/Silica-Lignin Composites. Int. J. Polym. Sci. 2016, 2016. [CrossRef]

14. Costiuc, L.; Tierean, M.; Baltes, L.; Patachia, S. Experimental Investigation on the heat of combustion for solid plastic waste mixtures. Environ. Eng. Manag. J. 2015, 14, 1295-1302. [CrossRef]

15. Sharuddin, S.D.A.; Abnisa, F.; Daud, W.M.A.W.; Aroua, M.K. Pyrolysis of plastic waste for liquid fuel production as prospective energy resource. IOP Conf. Ser. Mater. Sci. Eng. 2018, 334. [CrossRef]

16. Dayana, S.; Sharuddin, A.; Abnisa, F.; Mohd, W.; Wan, A. A review on pyrolysis of plastic wastes. Energy Convers. Manag. 2016, 115, 308-326. [CrossRef]

17. Miandad, R.; Barakat, M.A.; Aburiazaiza, A.S.; Rehan, M.; Nizami, A.S. Catalytic pyrolysis of plastic waste: A review. Process Saf. Environ. Prot. 2016, 102, 822-838. [CrossRef]

18. Almeida, D.; de Marque, M.F. Thermal and Catalytic Pyrolysis of Polyethylene Plastic Waste in Semi. Polimeros 2015, 26, 1-8.

19. Czajczyńska, D.; Anguilano, L.; Ghazal, H.; Krzyżyńska, R.; Reynolds, A.J.; Spencer, N.; Jouhara, H. Potential of pyrolysis processes in the waste management sector. Therm. Sci. Eng. Prog. 2017, 3, 171-197. [CrossRef]

20. Yang, X.; Itaya, Y.; Hatano, S.; Yamazaki, R.; Mori, S. Pryolysis behavior of refuse derived fuel. J. Chem. Eng. Jpn. 2001, 34, 91-94. [CrossRef]

21. Efika, E.C.; Onwudili, J.A.; Williams, P.T. Products from the high temperature pyrolysis of RDF at slow and rapid heating rates. J. Anal. Appl. Pyrolysis 2015, 112, 14-22. [CrossRef]

22. Porshnov, D.; Ozols, V.; Ansone-Bertina, L.; Burlakovs, J.; Klavins, M. Thermal decomposition study of major refuse derived fuel components. Energy Procedia 2018, 147, 48-53. [CrossRef]

23. Buah, W.K.; Cunliffe, A.M.; Williams, P.T. Characterization of products from the pyrolysis of municipal solid waste. Process Saf. Environ. Prot. 2007, 85, 450-457. [CrossRef]

24. Cozzani, V.; Petarca, L.; Tognotti, L. Devolatilization and pyrolysis of refuse derived fuels: Characterization and kinetic modelling by a thermogravimetric and calorimetric approach. Fuel 1995, 74, 903-912. [CrossRef]

25. Rajca, P.; Poskart, A.; Chrubasik, M.; Sajdak, M.; Zajemska, M.; Skibiński, A.; Korombel, A. Technological and economic aspect of Refuse Derived Fuel pyrolysis. Renew. Energy 2020, 161, 482-494. [CrossRef]

26. Yun, Y.M.; Seo, M.W.; Ra, H.W.; Koo, G.H.; Oh, J.S.; Yoon, S.J.; Kim, Y.K.; Lee, J.G.; Kim, J.H. Pyrolysis characteristics of glass fiber-reinforced plastic (GFRP) under isothermal conditions. J. Anal. Appl. Pyrolysis 2015, 114, 40-46. [CrossRef]

27. Haydary, J.; Susa, D.; Gelinger, V.; Čacho, F. Pyrolysis of automobile shredder residue in a laboratory scale screw type reactor. J. Environ. Chem. Eng. 2016, 4, 965-972. [CrossRef]

28. Zolezzi, M.; Nicolella, C.; Ferrara, S.; Iacobucci, C.; Rovatti, M. Conventional and fast pyrolysis of automobile shredder residues (ASR). Waste Manag. 2004, 24, 691-699. [CrossRef] [PubMed]

29. Roh, S.A.; Kim, W.H.; Yun, J.H.; Min, T.J.; Kwak, Y.H.; Seo, Y.C. Pyrolysis and gasification-melting of automobile shredder residue. J. Air Waste Manag. Assoc. 2013, 63, 1137-1147. [CrossRef] [PubMed]

30. Singh, R.K.; Ruj, B. Time and temperature depended fuel gas generation from pyrolysis of real world municipal plastic waste. Fuel 2016, 174, 164-171. [CrossRef]

31. Han, S.; Jang, Y.C.; Choi, Y.S.; Choi, S.K. Thermogravimetric kinetic study of automobile shredder residue (ASR) pyrolysis. Energies 2020, 13, 1451. [CrossRef]

32. Goodwin, D.G.; Moffat, H.K.; Speth, R.L. Cantera: An Object-Oriented Software Toolkit for Chemical Kinetics, Thermodynamics, and Transport Processes. Version 2.3.0. 2017. Available online: https://zenodo.org/record/170284\#.YFiWdOh (accessed on 1 March 2021). [CrossRef]

33. Pejpichestakul, W.; Ranzi, E.; Pelucchi, M.; Frassoldati, A.; Cuoci, A.; Parente, A.; Faravelli, T. Examination of a soot model in premixed laminar flames at fuel-rich conditions. Proc. Combust. Inst. 2019, 37, 1013-1021. [CrossRef]

34. Smith, G.P.; Golden, D.M.; Frenklach, M.; Moriarty, N.W.; Eiteneer, B.; Goldenberg, M.; Bowman, C.T.; Hanson, R.K.; Song, S.; Gardiner, W.C.; et al. GRI-Mech 3.0. Available online: http://www.me.berkeley.edu/gri_mech/ (accessed on 1 March 2021).

35. International Organization for Standardization. Solid Biofuels—Determination of Ash Content; ISO EN 14775:2010; International Organization for Standardization: Geneva, Switzerland, 2010.

36. British Standard Institution. Solid Biofuels_Determination of the Content of Volatile Matter; BS EN 15148:2009; British Standard Institution: London, UK, 2009.

37. International Organization for Standardization. Solid Mineral Fuels-Determination of Gross Calorific Value by the bomb Calorimetric Method and Calculation of net Calorific Value; ISO 1928:2009; International Organization for Standardization: Geneva, Switzerland, 2009.

38. Hahladakis, J.N.; Velis, C.A.; Weber, R.; Iacovidou, E.; Purnell, P. An overview of chemical additives present in plastics: Migration, release, fate and environmental impact during their use, disposal and recycling. J. Hazard. Mater. 2018, 344, 179-199. [CrossRef] 
39. Mallick, P.K. Failure of polymer matrix composites (PMCs) in automotive and transportation applications. In Failure Mechanisms in Polymer Matrix Composites; Woodhead Publishing Limited: Cambridge, UK, 2012.

40. Djokic, M.R.; Van Geem, K.M.; Cavallotti, C.; Frassoldati, A.; Ranzi, E.; Marin, G.B. An experimental and kinetic modeling study of cyclopentadiene pyrolysis: First growth of polycyclic aromatic hydrocarbons. Combust. Flame 2014, 161, 2739-2751. [CrossRef]

41. Sánchez, N.E.; Millera, Á.; Bilbao, R.; Alzueta, M.U. Polycyclic aromatic hydrocarbons (PAH), soot and light gases formed in the pyrolysis of acetylene at different temperatures: Effect of fuel concentration. J. Anal. Appl. Pyrolysis 2013, 103, 126-133. [CrossRef]

42. Szewczyk, D.; Ślefarski, R.; Jankowski, R. Analysis of the combustion process of syngas fuels containing high hydrocarbons and nitrogen compounds in Zonal Volumetric Combustion technology. Energy 2017, 121, 716-725. [CrossRef] 